\title{
ELPIS: a dataset of local-scale daily climate scenarios for Europe
}

\author{
M. A. Semenov ${ }^{1, *}$, M. Donatelli ${ }^{2,3}$, P. Stratonovitch ${ }^{1}$, E. Chatzidaki ${ }^{2}$, B. Baruth ${ }^{2}$ \\ ${ }^{1}$ Centre for Mathematical and Computational Biology, Rothamsted Research, Harpenden, Herts AL5 2JQ, UK \\ ${ }^{2}$ European Commission - Joint Research Centre, Ispra, Italy \\ ${ }^{3}$ Agriculture Research Council CRA-CIN, Via di Corticella 133, 40128 Bologna, Italy
}

\begin{abstract}
We developed a dataset of local-scale daily climate scenarios for Europe, called ELPIS. This dataset is based on $25 \mathrm{~km}$ grids of interpolated daily precipitation, minimum and maximum temperatures and radiation from the European Crop Growth Monitoring System (CGMS) meteorological dataset and climate predictions from the multi-model ensemble of 15 global climate models that were used in the IPCC 4th Assessment Report. The site parameters for the distributions of climatic variables have been estimated by the LARS-WG weather generator for nearly 12000 grids for the period 1982-2008. Using changes in climate predicted by global climate models, we perturbed site parameters for the baseline climate to generate local-scale daily climate scenarios for the future under several emission scenarios. The ability of LARS-WG to reproduce daily weather for the period 1982-2008 was assessed using statistical tests. This prototype dataset was designed for use in conjunction with process-based impact models (e.g. crop simulation models) for the assessment of climate change impacts in Europe. A climate scenario generated by LARS-WG for a grid represents daily weather at a typical site from this grid that is used for agricultural production. This makes it different from the recently developed $25 \mathrm{~km}$ gridded dataset for Europe (E-OBS), which gives the best estimate of grid box averages to enable direct comparison with regional climate models.
\end{abstract}

KEY WORDS: Climate change - Impact assessment - Weather generator - Spatial interpolation LARS-WG · Crop Growth Monitoring System· CGMS · ELPIS

\section{INTRODUCTION}

With the advent of climate predictions in the form of multi-model ensembles that are constructed by running several global or regional climate models for a common set of experiments, studies on impact assessment of climate change have the potential to predict not only the magnitude of the impact, but also the uncertainty of predictions. The uncertainty in climate projections in a multi-model ensemble is the result of structural differences between individual climate models as well as variations in initial conditions or model parameterisations (Semenov \& Stratonovitch 2010).

The direct use of climate predictions from the IPCC Assessment Report 4 (AR4) multi-model ensemble for impact assessments could be problematic because Global Climate Model (GCM) predictions are typically available as monthly means or changes in monthly means of climatic variables on a coarse spatial resolution. However, process-based impact models require daily weather time series as one of their main inputs (Lawless \& Semenov 2005, Willis et al. 2006, Semenov 2008a). Even when daily output is available from GCMs, a large uncertainty in the output at a daily scale, particularly for precipitation, means that it is not appropriate for direct use with impact models and analyses of extreme events (Semenov 2007). Output from GCMs requires application of various downscaling techniques (Barrow et al. 1996, Bardossy 1997, Wilby et al. 1998, Mearns et al. 1999, Murphy 1999, Salon et al. 2008). One of the downscaling techniques to create local-scale daily climate scenarios makes use of a stochastic weather generator (Wilks 1992, Barrow \& Semenov 1995, Wilks \& Wilby 1999, Semenov 2007). 
In a recent paper Semenov \& Stratonovitch (2010) describe the LARS-WG weather generator, which incorporates climate predictions from the multi-model ensemble used in the IPCC AR4 (Solomon et al. 2007). To generate local-scale daily scenarios for the future, LARS-WG perturbs site-specific distributions of climate variables for the 'baseline' period by applying changes in climate predicted by the GCMs from the AR4 multi-model ensemble. However, before one can generate a future climate scenario at a site, the 'baseline' site parameters for the distributions of climatic variables need to be estimated using 20-30 yr of observed daily weather. This step can be made redundant if site parameters have already been estimated and are available for the region of interest.

The aims of this paper are to (a) estimate the LARSWG site parameters across Europe by utilising the daily weather for the period 1982-2008 at a $25 \mathrm{~km}$ grid available from the Crop Growth Monitoring System (CGMS) meteorological dataset, and (b) assess the performance of LARS-WG at all CGMS grids. As a result of this project, a dataset of the LARS-WG site parameters for nearly 12000 grids across Europe has been created (see Fig. 1). Using a dataset of site parameters, like the one prototyped, combined with climate predictions from the AR4 multi-model ensembles, local-scale daily climate scenarios can be generated by LARS-WG for a suite of climatic variables and used in impact assessments across Europe. We have named this combined dataset ELPIS.

High-resolution gridded datasets of daily climatic variables have been constructed in the past for Europe (Frei \& Schär 1998, Haylock et al. 2008). Recently, the $25 \mathrm{~km}$ gridded dataset for Europe (E-OBS) was constructed as part of the EU-FW6 ENSEMBLES project (Haylock et al. 2008). This dataset consists of daily data for precipitation and minimum, maximum and mean surface temperatures for the period 1950-2006, which was spatially interpolated from observed site weather available through the European Climate Assessment and Data dataset (ECA\&D; http://eca.knmi.nl/) (Klok \& Tank 2009). E-OBS improves on the spatial resolution and extent, time period and number of contributing stations of the previous datasets. However, E-OBS does not provide observed or estimated daily global radiation, which are required (e.g. by crop simulation models) for prediction of crop growth and are used in the assessment of the impact of climate change on crop production in Europe. Moreover, the primary goal of constructing the E-OBS gridded dataset was to use gridded data for validation of Regional Climate Models (RCMs). A comparison between model output and interpolated gridded data assumes that the observations and the model represent processes at the same spatial scale. Regional climate models represent area- averaged rather than site processes. Therefore, each grid value in E-OBS is an estimate that is averaged over the grid square.

The rationale behind the interpolation procedure in the CGMS meteorological dataset was to create daily weather that is representative for a typical site from a grid, which could be used for assessment of agricultural risk based on crop simulation models. The CGMS meteorological dataset includes a suite of climate variables: precipitation, minimum and maximum temperatures, radiation, wind speed, minimum and maximum air relative humidity that are required on a daily scale by crop simulation models. Table 1 shows the number of sites for each climatic variable that are available from CGMS and ECA\&D datasets. Fig. 1 shows the locations of sites with observed daily weather that were used for spatial interpolation at $25 \mathrm{~km}$ grids across Europe along with the grid-masks for the CGMS and the E-OBS gridded datasets.

\section{THE CGMS METEOROLOGICAL DATASET}

The CGMS was developed within the framework of the MARS project (Monitoring of Agriculture by Remote Sensing), which was established following a decision of the Council of Ministers of the European Commission (EC) in 1988. CGMS is used at the Joint Research Centre (JRC) of the EC to predict yields of major agricultural crops in the European Union (EU) for the EC's Directorate General for Agriculture and the European Statistical Office (EUROSTAT). With the expansion of the EU, CGMS now covers all of the 27 Member States, and also includes Belarus, Ukraine, Moldova, Turkey, western Russia and parts of northern Africa (Fig. 1C).

CGMS is built around 3 models: WOFOST and LINGRA, developed by the DLO-Winand Staring Centre and the Research Institute for Agrobiology and Soil Fertility, respectively, both located in Wageningen,

Table 1. Number of sites in the Crop Growth Monitoring System (CGMS, 1982-2008) and the European Climate Assessment and Data (ECA\&D, 1950-2006) datasets where climatic variables were observed at least for part of the reference period. Data in parentheses are percentages of ECA\&D sites that are publicly available. Variables which were spatially interpolated to $25 \mathrm{~km}$ grids in each dataset are marked with *

\begin{tabular}{|lcc|}
\hline Climate variable & CGMS & ECA\&D \\
\hline Precipitation & $* 2581$ & ${ }^{*} 2052(48)$ \\
Maximum temperature & ${ }^{*} 2855$ & ${ }^{*} 1368(48)$ \\
Minimum temperature & $* 2855$ & ${ }^{*} 1371(48)$ \\
Radiation & ${ }^{*} 386$ & - \\
Sunshine duration & 1140 & $184(59)$ \\
Cloud cover & 2128 & $128(70)$ \\
\hline
\end{tabular}



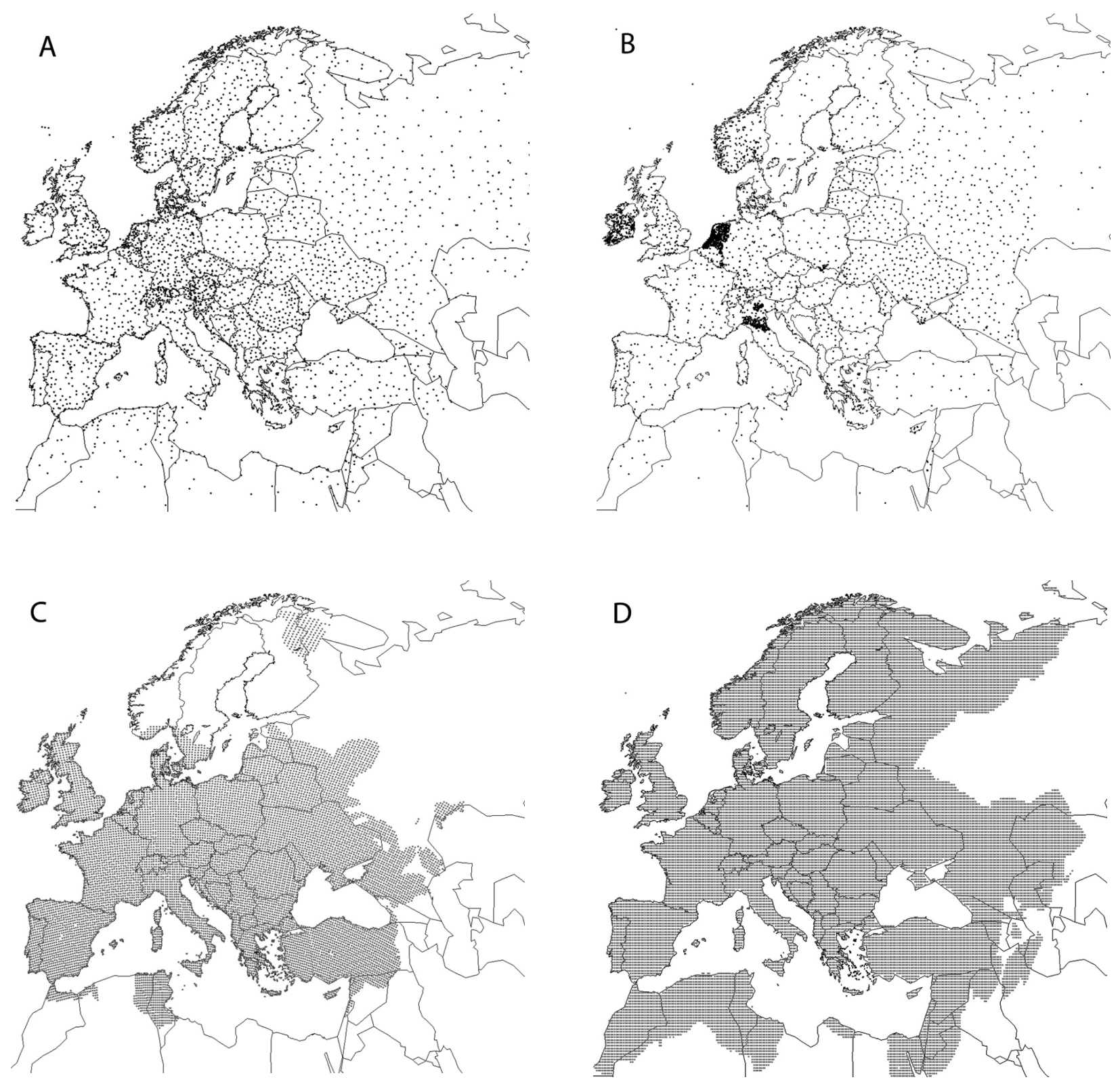

Fig. 1. Sites (dots) with observed daily weather that were used for spatial interpolation to $25 \mathrm{~km}$ grids from (A) the Crop Growth Monitoring System (CGMS) and (B) the European Climate Assessment and Data (ECA\&D) datasets, and grid-masks (hatching) of interpolated daily weather for (C) the CGMS dataset and (D) the E-OBS dataset

The Netherlands; and WARM, jointly developed by the Department of Crop Production, University of Milan, Italy, and the JRC, MARS Unit. WOFOST is a crop simulation model that is used to predict growth of a number of agricultural crops by using different sets of parameters that are calibrated for individual crops (van Diepen et al. 1989). The LINGRA (LINTUL GRAssland) model was developed to predict growth of perennial rye grass (Schapendonk et al. 1998, Rodriguez et al. 1999). WARM (Water Accounting Rice Model) is a model for simulating rice growth, which ac- counts for biotic and abiotic stresses (Confalonieri et al. 2009, 2010).

Daily weather data, which are required by crop simulation models as a major model input, were collected from about 3000 sites in Europe (see Table 1 and Fig. 1) for CGMS. This site-specific daily weather data was interpolated to the $25 \mathrm{~km}$ grid level. Interpolated gridded daily values represent values that could be considered as typical for the part of the grid that is used for agricultural production. Hence, each weather data series represents neither the daily weather at the grid 
centre nor area-average grid values. The following is a brief description of interpolation procedures that were used to develop the CGMS meteorological dataset (van der Goot 1997). The dataset is periodically reprocessed, adding time series and running updated data quality evaluation procedures.

\subsection{Observed weather data}

Daily precipitation and temperature records are usually available for most sites used in CGMS. Some of the meteorological variables needed for a crop simulation model (e.g. radiation) are often missing and, therefore, have to be estimated.

When daily radiation data is missing, but measurements of daily sunshine duration are available, CGMS uses the Ångström-Prescott equation to estimate daily radiation (Ångström 1924, Prescott 1940):

$$
R=R_{0}\left(a+b \frac{S}{D}\right)
$$

where $R$ is the daily global radiation $\left(\mathrm{MJ} \mathrm{m}^{-2} \mathrm{~d}^{-1}\right), R_{0}$ is the daily extraterrestrial radiation $\left(\mathrm{MJ} \mathrm{m}^{-2} \mathrm{~d}^{-1}\right), S$ is the daily sunshine duration (h), $D$ is the astronomical daylength (h), and $a$ and $b$ are empirical constants.

When both daily radiation and daily sunshine duration are missing, CGMS estimates daily radiation from the difference between the maximum and the minimum temperatures using the following equation (Hargreaves et al. 1985):

$$
R=R_{0} a \sqrt{\left(T_{\max }-T_{\min }\right)}+C
$$

where $T_{\max }$ and $T_{\min }$ are the daily maximum and minimum temperatures $\left({ }^{\circ} \mathrm{C}\right)$, and $a$ and $c$ are empirical constants.

When daily cloud cover is also available, CGMS uses the following equation for daily radiation (Supit \& van Kappel 1998):

$$
R=R_{0} a \sqrt{\left(T_{\max }-T_{\min }\right)}+b \sqrt{(1-0.125 W)}+c
$$

where $W$ is the mean of the total cloud cover (octa), and $a, b$ and $c$ are empirical constants.

Supit \& van Kappel (1998) estimated empirical constants for the above equations for 256 reference sites where observed daily radiation was available. The sets of empirical constants were spatially interpolated across Europe by a simple distance-weighted average algorithm using reference sites.

\subsection{Interpolation methodology}

The first step of the interpolation procedure from the site to the grid level is the selection of the sites that rep- resent meteorological conditions for a grid. The second step is the interpolation of the climatic variables for a grid using selected sites (van der Goot 1997).

To establish the suitability of a site for interpolation, a site score that reflects the similarity between that site and the grid centre is calculated. This score takes into account the following characteristics: (a) distance to the grid centre, (b) difference in altitude, (c) difference in distance to the coast, and (d) separation by a climatic barrier. The score $\left(S R_{\text {site }}\right)$ is calculated as follows (van der Goot 1997):

$$
S R_{\text {site }}=D+W_{\text {alt }} \Delta_{\text {alt }}+\Delta_{\text {coast }}+\Delta_{\text {barrier }}
$$

where $D$ is the distance between the weather station and the grid centre $(\mathrm{km}) ; \Delta_{\text {alt }}$ is an absolute difference in altitude $(\mathrm{m}) ; W_{\text {alt }}$ is a weighting factor $\left(\mathrm{km} \mathrm{m}^{-1}\right) ; \Delta_{\text {coast }}$ is an absolute difference in corrected distance to the coast $(\mathrm{km}) ; \Delta_{\text {barrier }}$ is the climate barrier increment $(\mathrm{km})$. The climate barrier increment is set to 1000 when the station and the grid centre are separated by a climate barrier; otherwise it is set to 0 . The more similar a site is to the grid centre, the lower the score.

The second step is interpolation of the climatic variables. In the current implementation of CGMS, precipitation data is not interpolated. The precipitation for a grid is taken from the site with the lowest score.

Daily temperature and radiation are interpolated using data from a set of sites (up to 4 sites). To determine which stations and how many stations to use, a set score is calculated as follows (van der Goot 1997):

$$
S R_{\text {set }}=\underset{\text { site } \in \text { set }}{\operatorname{mean}}\left(S R_{\text {site }}\right)+D_{\text {cg }}+F_{\mathrm{N}_{\text {site } \in \text { set }}}\left(S R_{\text {site }}\right)
$$

where $D_{\mathrm{cg}}$ is the distance between the grid centre and the centre of gravity of the set of sites $(\mathrm{km})_{i} F_{\mathrm{N}}$ is a factor based on the number of stations in the set (it is 0 for 3 or 4 sites in the set, 0.2 for 2 sites, and 0.5 for a set consisting of a single site). Calculation of the set score is carried out for all combinations of up to 4 sites, which are taken from the 7 sites with the smallest site score.

Once the set of sites with the smallest set score has been selected for interpolation, daily minimum and maximum temperatures and daily radiation are simply averaged. For temperature, the result of the averaging is corrected for the difference in altitude between the centre of gravity of the set and the grid centre.

\section{ELPIS DATASET OF CLIMATE SCENARIOS}

The ELPIS dataset consists of a set of site parameters for the LARS-WG weather generator calculated for approx. 12000 twenty-five $\mathrm{km}$ grids from the CGMS meteorological dataset, combined with climate predic- 
tions from the AR4 multi-model ensemble of global climate models. For each grid, which contains $27 \mathrm{yr}$ of daily weather for the period 1982-2009, the LARS-WG weather generator was used to calculate site parameters for the distributions of 4 climatic variables: daily precipitation, maximum and minimum temperatures, and radiation. These site parameters (called the baseline) can be used by LARS-WG to generate synthetic local-scale daily weather time series of arbitrary length, which would be statistically similar to CGMS observed weather data for the reference period 19822009. When site parameters are combined with predictions from a global or regional climate model, future climate scenarios can be generated by LARS-WG. Predicted changes in mean and variability of climate, which can be derived from a climate model, are used to perturb site parameters for the baseline climate. This section assesses the performance of LARS-WG for the CGMS European dataset by comparing simulated and CGMS daily weather time series for each grid using several statistical tests, including the nonparametric Kolmogorov-Smirnov (K-S) test to compare probability distributions, and the $t$-test to compare means of climatic variables. In the last part of this section, the multi-model ensemble of climate predictions from 15 global climate models used in the IPCC AR4, which has been incorporated into LARS-WG, is briefly described (Semenov \& Stratonovitch 2010).

\subsection{LARS-WG weather generator}

LARS-WG is a stochastic weather generator based on the series approach (Racsko et al. 1991). A detailed description of the new version 5 is given by Semenov \& Stratonovitch (2010). LARS-WG produces daily time series of maximum and minimum temperatures, precipitation and solar radiation. It uses observed daily weather for a given site to compute a set of parameters for probability distributions of weather variables as well as correlations between them. It also uses flexible semi-empirical distributions to model climatic variables that have proven to be adequate for the simulation of daily weather across diverse climates and was able to reproduce extreme weather events (Semenov 2008b). By perturbing parameters of these distributions for a site using changes predicted from a global or regional climate model, local-scale daily climate scenarios can be generated for a site and used as input to a process-based model for impact assessments. LARSWG has been tested across diverse climates and has demonstrated good performance in reproducing various weather statistics (Semenov et al. 1998, Semenov 2008b). It is available at www.rothamsted.bbsrc.ac.uk/ mas-models/larswg.php.

\subsection{Performance of LARS-WG for the CGMS meteorological dataset}

We used 2 statistical tests to compare observed and simulated weather data. To compare the distributions of climatic variables, we used the 2-sample K-S test, which is a nonparametric test of equality of 1-dimensional probability distributions across 2 data samples. The K-S statistic quantifies the distance between the empirical cumulative distribution functions of the 2 samples. The null hypothesis is that the samples are drawn from the same continuous probability distribution. There are no restrictions on the shape of the distribution. The 2-sample K-S test is one of the most useful and general nonparametric methods for comparing 2 samples because it is sensitive to differences in both location and shape of the empirical cumulative distribution functions of the 2 samples. However, this generality comes at some cost and other tests (e.g. the Student's $t$-test) may be more sensitive if the data meet the assumptions underlying the test.

The second test we used was the Student's $t$-test, which compares the means of 2 normally distributed samples. The $t$-test is known to be robust since it continues to work well even when samples are not normally distributed. In fact, the Central Limit Theorem shows that the $t$-test can be applied to non-normal datasets if the samples are sufficiently large (Press et al. 2002). This is important because users of statistical tests often do not know if their dataset meets the criteria intended by the creator of the test. We used implementations of these 2 statistical tests as described in Press et al. (2002).

For each of nearly 12000 grids from the CGMS meteorological dataset, we performed statistical tests to compare the seasonal (DJF, MAM, JJA, SON) distributions of the dry and wet series (4 tests for each type of series, dry or wet), daily precipitation, maximum and minimum temperatures and radiation for each month (12 tests for each variable), and the monthly means of daily precipitation, maximum and minimum temperatures and radiation (12 tests for each variable). We used the K-S test to compare distributions and $t$-test to compare means. The significance level was set to $\alpha=$ 0.01 .

For each grid, we counted the number of significant results for statistical tests in each group at the $\alpha=0.01$ significance level. In traditional statistical hypothesis testing, $\alpha$ is the probability that the test will give a significant result when the null hypothesis is true, i.e. the means of 2 distributions are equal. If the observed $\mathrm{p}$-value is smaller than the significance level, then the null hypothesis is rejected. Therefore, even when the null hypothesis is in fact true, we can reject it with the probability $\alpha=0.01$ (the so-called 'false positive' or 
Type I error). In Fig. 2, we plotted the proportion of grids that showed significant results for exactly $k$ statistical tests as a function of $k$. For the seasonal distribution of the wet and dry series, the proportion of grids with exactly one significant result for the K-S test was 0.048 for the wet series and 0.0079 for the dry series (Fig. 2A). Considering that 4 tests were performed for each grid to compare wet or dry series, the proportion of significant results per test performed was 0.012 for the wet series and 0.002 for the dry series. This agrees with the expected number of "false positives" for testing the null hypothesis that both samples came from the same distribution. Similar conclusions can be obtained for testing the distribution of daily precipitation for individual months and for monthly mean precipitation (Fig. 2B), and for the monthly means of maximum and minimum temperatures (Fig. 2C). However, for monthly means of daily radiation, the proportion of significant results was higher than that expected by chance, at 0.021 (Fig. 1D). This needs to be investigated further, as it suggests that the observed distribution is not successfully reproduced in the simulation. There were no significant results when comparing the distributions of daily minimum or maximum temperatures, or daily radiation using the K-S test.

In Fig. 3, we presented the grids that have 1, 2, 3 or 4 significant test results for selected climatic variables. There are very few grids with $>1$ significant result for the K-S test for seasonal distributions of the dry and wet series (Fig. 3A). These grids are located in south- ern Europe and North Africa, where the climate is characterised by very long dry periods. In Fig. 4A, the observed and simulated mean length of the dry or wet series for individual months are presented for 3 grids (24106, Tunisia; 47164, Greece; and 47071, Spain) which had 2 or more significant test results for the K-S tests of the seasonal distributions of the dry and wet series. Even for these grids, the mean length of the dry and wet series are reproduced relatively accurately. For example, the observed mean length of the dry series starting in June in Tunisia exceeded 100 d, whereas the simulated value was $90 \mathrm{~d}$ (Fig. 4A).

Monthly precipitation means were simulated very well across the whole dataset. The results of the $t$-test are presented in Fig. 3C. Distributions of daily precipitation for each month were compared using the K-S test (Fig. 3B). There were grids in southern Europe where test results were significant for 2 or 3 mo (Greece, Algeria, Turkey) and even 4 mo (Israel) out of 12. In Fig. $4 \mathrm{~B}$, the observed vs. simulated monthly mean precipitation are presented for 3 grids $(24100$, Algeria; 42204, Israel; and 42156, Greece). The $t$-tests showed differences in means for summer months with very low precipitation (1 to $3 \mathrm{~mm} \mathrm{mo}^{-1}$ ). LARS-WG slightly overestimated these low summer precipitation values, which resulted in significant test statistics. However, this difference in means would have very little effect when used, e.g. in conjunction with a crop simulation model (Semenov et al. 1993, Semenov et al. 1996).

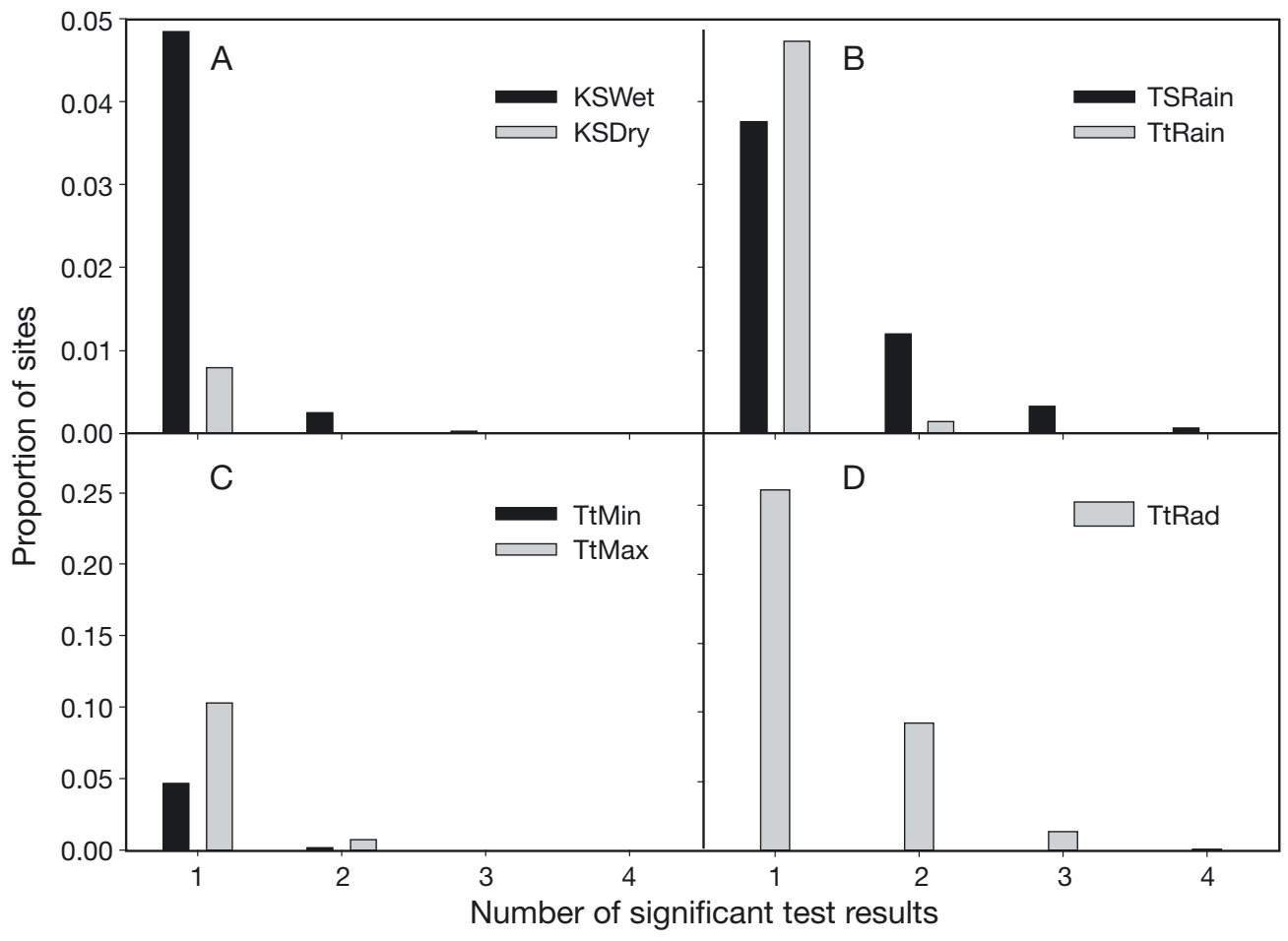

Fig. 2. Proportion of CGMS grids with the number of significant test results $(=1$, 2,3 or 4 ) at the significance level $\alpha=0.01$ for (A) the $\mathrm{K}-\mathrm{S}$ test for the seasonal distributions of the dry (KSDry) and wet (KSWet) series, (B) the K-S test for the distributions of precipitation (TSRain) and $t$-test (TtRain) for monthly means of daily precipitation, (C) the $t$-test for monthly means of maximum (TtMax) and minimum (TtMin) daily temperatures, and (D) the $t$-test (TtRad) for monthly means of daily radiation. Note the different scales used for A, B and C, D. The K-S test for the monthly distributions of daily minimum and maximum temperatures and daily radiation showed no significant test results 

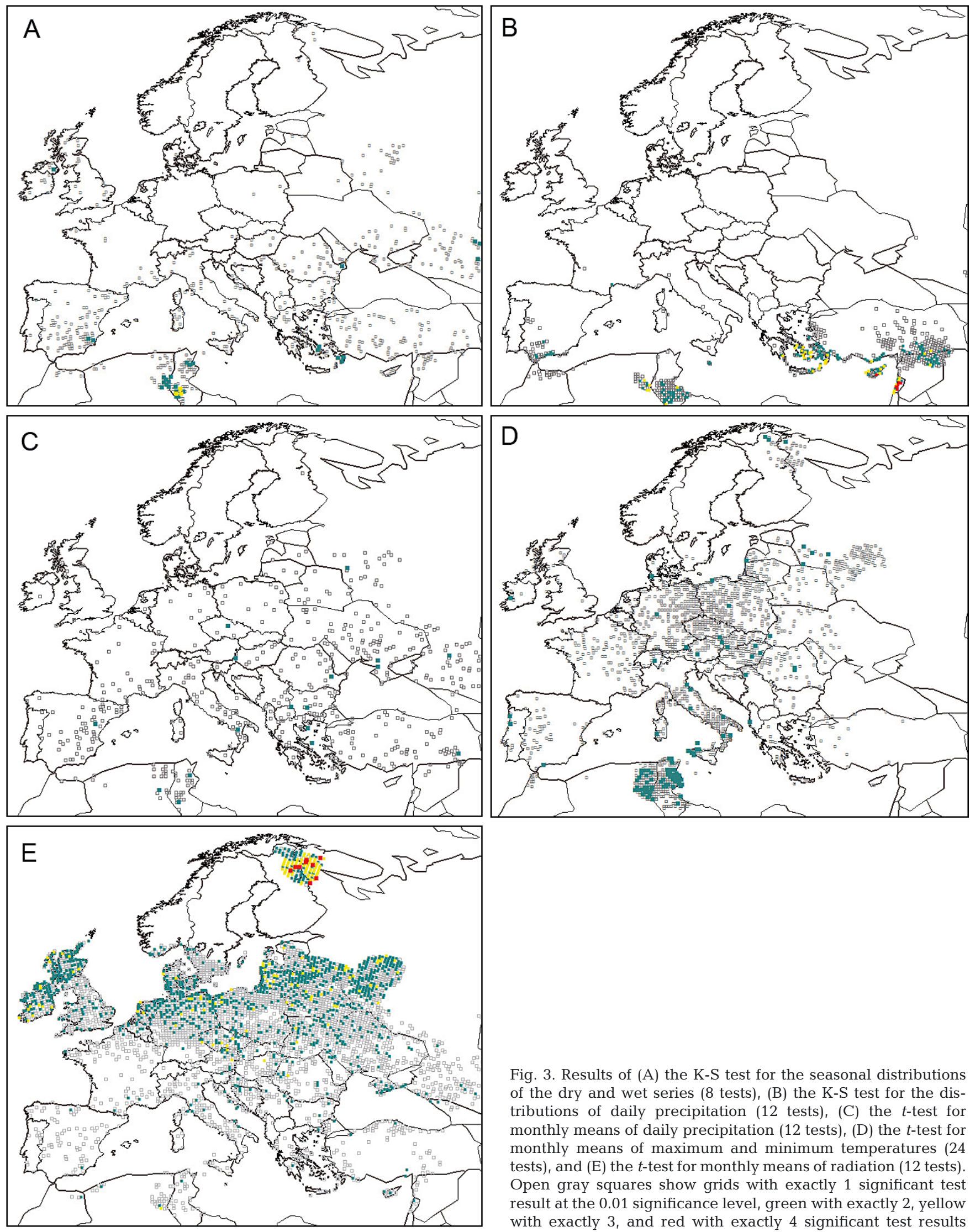

Fig. 3. Results of (A) the K-S test for the seasonal distributions of the dry and wet series (8 tests), (B) the K-S test for the distributions of daily precipitation (12 tests), (C) the $t$-test for monthly means of daily precipitation (12 tests), (D) the $t$-test for monthly means of maximum and minimum temperatures (24 tests), and (E) the $t$-test for monthly means of radiation (12 tests). Open gray squares show grids with exactly 1 significant test result at the 0.01 significance level, green with exactly 2 , yellow with exactly 3 , and red with exactly 4 significant test results 

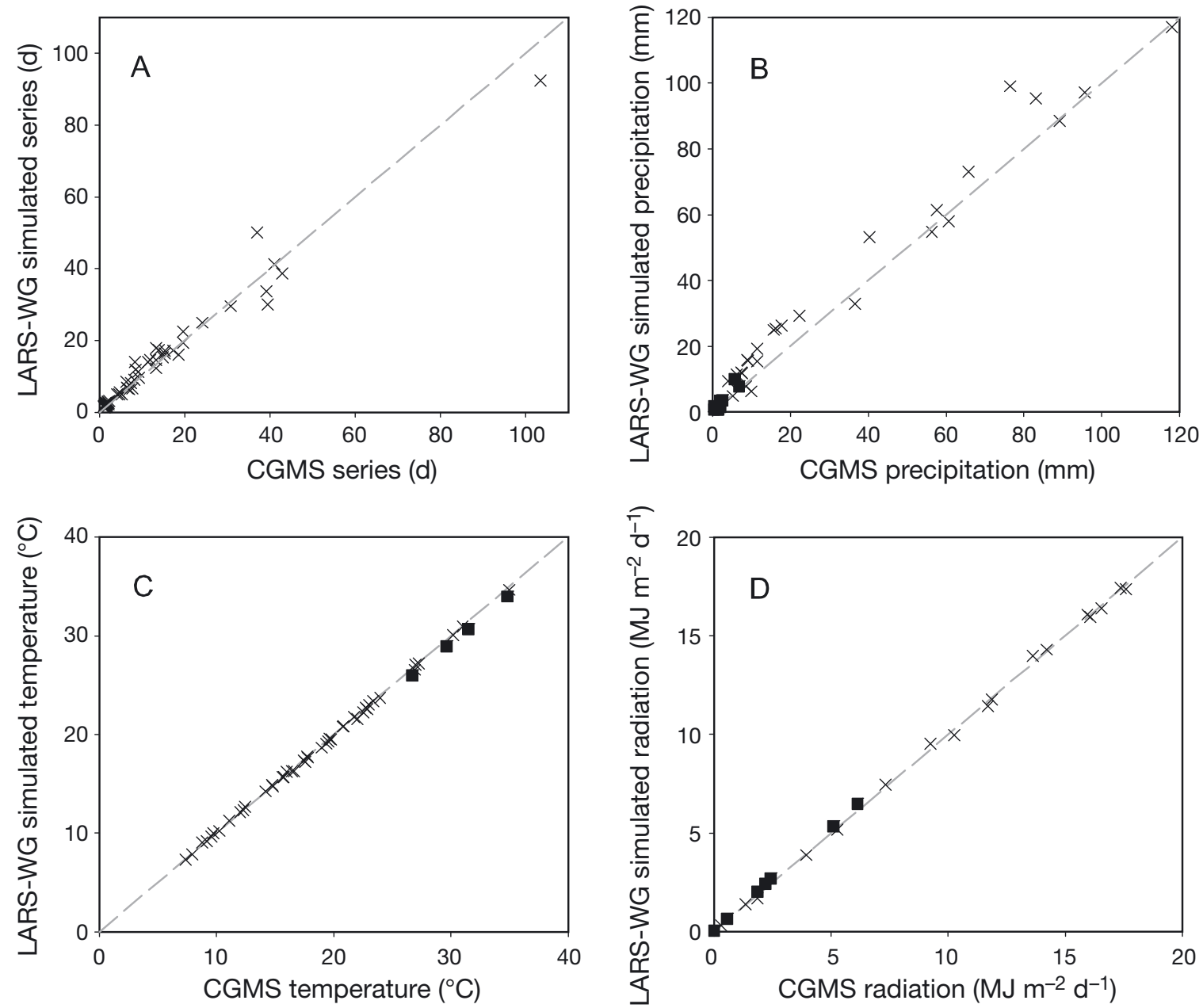

Fig. 4. Plots of CGMS vs. LARS-WG monthly means (12 values for a selected climatic variable at a selected grid) for (A) the dry and wet series (grids 24106, Tunisia; 47164, Greece; 47071, Spain), (B) monthly mean precipitation (grids 24100, Algeria; 42204, Israel; 42156, Greece), (C) maximum and minimum temperatures (grids 45125, Sicily; 34111, Tunisia), and (D) radiation (grids 177140, Finland; 129076, Scotland). Grids were selected for variables where the performance of LARS-WG was poorest. (घ) Months with significant $t$-test results at $\alpha=0.01$. No statistical comparison was made for the monthly means of the dry and wet series

There were no significant results for the K-S test of distributions of daily maximum or minimum temperature or daily radiation for individual months for all grids. However, when the monthly means of the maximum or minimum temperatures were compared, up to $2 t$-test results were significant for grids in Tunisia and Algeria. Fig. 4C shows the observed vs. simulated monthly means of the maximum and minimum temperatures at 2 grids (45125, Sicily; and 34111, Tunisia). The $t$-test results were significant for June and July at both grids, as the mean maximum temperature was slightly underestimated (by $<1^{\circ} \mathrm{C}$ ).

The $t$-test for monthly mean radiation showed many significant results in northern Europe. For northern Finland, grids with 3 or even 4 significant test results were commonplace. Fig. 4D shows the observed vs. simulated monthly mean radiation at 2 grids $(177140$,
Finland; and 129076, Scotland). Monthly mean radiation for the winter months in northern Finland is very low. Even a small difference between the observed and simulated mean values could result in a significant test result. For example, the observed monthly mean radiation figures at grid 177140, Finland for October, November and December were 2.19, 0.56 and 0.01 (MJ $\mathrm{m}^{-2} \mathrm{~d}^{-1}$ ) compared with simulated values of $2.43,0.65$ and 0.04 ; nevertheless, $t$-test statistics were significant. These small differences between observed and simulated radiation for low radiation values are unlikely to cause large errors in impact assessment, e.g. in simulation of crop yields.

In summary, the overall performance of LARS-WG in selected statistical tests was good and climate scenarios generated by LARS-WG can be used with confidence in process-based models for impact assessment. 


\subsection{IPCC AR4 multi-model ensemble climate scenarios}

The ELPIS dataset provides the LARS-WG site parameters at $25 \mathrm{~km}$ grids across Europe for the period 1982-2008. Combined with predictions from a global climate model, LARS-WG can be used to generate local-scale daily climate scenarios for the future.

The LARS-WG weather generator incorporates predictions from 15 global climate models that were used for the impact assessment in the IPCC AR4 (Solomon et al. 2007). These complex computer models describe the general circulation of a planetary atmosphere and ocean, and are based on physics equations (the Navier-Stokes equations) with thermodynamic terms for various energy sources (radiation, latent heat). Climate is described at a finite number of grid points (a grid point model) or by a finite number of mathematical functions (a spectral model). The limiting factor for running GCMs is computational power. A compromise must be reached between the spatial resolution of the model and the computer time required to perform a climate simulation. As a result, most GCMs tend to have a coarse spatial resolution, which leads to approximations in the model representation of meteorological variables at the regional or local scale. These so-called 'sub-grid scale' processes have to be parameterised in the model, rather than be solved realistically as a function of the fundamental equations. However, despite these limitations, GCMs are the best option to examine the evolution of climate under a variety of conditions (Solomon et al. 2007).

Table 2 summarises important features of these GCMs from the AR4 multi-model ensemble, including grid resolution, available emission scenarios (Nakicenovic \& Swart 2000) and their reference time periods for climate predictions. Climate models are referred to in LARS-WG by their acronyms used in AR4 (Table 2). For most of the GCMs from the IPCC AR4 multi-model ensemble, climate predictions are available for the following SRES emission scenarios: B1, A1B and A2. The key assumptions of the SRES emission scenarios and corresponding increases in $\mathrm{CO}_{2}$ concentrations are given in Table 3 (Nakicenovic \& Swart 2000). All of these GCMs are coupled atmosphere-ocean models and most of them were run for the period 1960-2100. The output from these GCMs are available as monthly means of climatic variables, including precipitation, maximum and minimum temperatures and radiation, for the baseline period corresponding to 1960-1990, 2020 (corresponding to 20112030), 2055 (corresponding to 2046-2065) and 2090 (corresponding to 2081-2100). Some of the climate centres made 2 independent runs of their GCMs available, which differed in their initial conditions and/or model parameterization. Only output from the first run for each GCM has been used by LARS-WG.
To generate climate scenarios at a site for, e.g. 2020 and the A1B emission scenario, the LARS-WG 'baseline' parameters corresponding to 1982-2009 are adjusted by using the $\Delta$-changes predicted by GCM for 2020 for the A1B emission scenario. These $\Delta$-changes are spatially interpolated for the site using adjacent grids to smooth stepwise grid values. If 'baseline' parameters were calculated for a period that is different from the GCM's baseline period of 1960-1990, then an appropriate correction to $\Delta$-changes to account for this difference is applied. Monthly predictions for each GCM from the AR4 multi-model ensemble are available for minimum and maximum temperatures (only for mean temperature for some GCMs), precipitation and radiation. $\Delta$-changes are calculated as relative changes for precipitation and radiation, and absolute changes for minimum and maximum temperatures. No adjustments for the distributions of the dry and wet series and temperature variability are made because this would require access to the daily outputs from the GCMs, which are not readily available from the IPCC Data Centre.

Climate predictions from each GCM from the multimodel ensemble should be treated as equally probable predictions of the evolution of climate. The use of a multi-model ensemble of scenarios combined with a process-based impact model allows us to quantify the uncertainty in impacts of climate change (Semenov \& Stratonovitch 2010).

\subsection{Derived weather variables}

Daily weather variables other than the ones generated by LARS-WG could be required to run impact models such as crop growth models and disease models. Wind speed, minimum and maximum relative humidity and reference evapotranspiration could be generated using the software components of the CLIMA weather generator framework (Donatelli et al. 2006). Specifically, average daily wind speed was generated using skewed normal probability density function via the component 'wind' (Donatelli et al. 2009), assuming the same pattern of Wind variability at each given site. Daily minimum and maximum values of relative humidity were estimated using the modelling solutions evaluated by Bregaglio et al. (2010). Finally, reference evapotranspiration was estimated using the Penman-Monteith model as implemented in the new version of the evapotranspiration (ET) software component (Donatelli et al. 2006).

Some disease simulation models require hourly inputs and the estimation of leaf wetness. A modelling solution based on CLIMA software components, including the LeafWetness component, is available for generating this hourly data. Hourly data can be generated via the dedicated software component. 


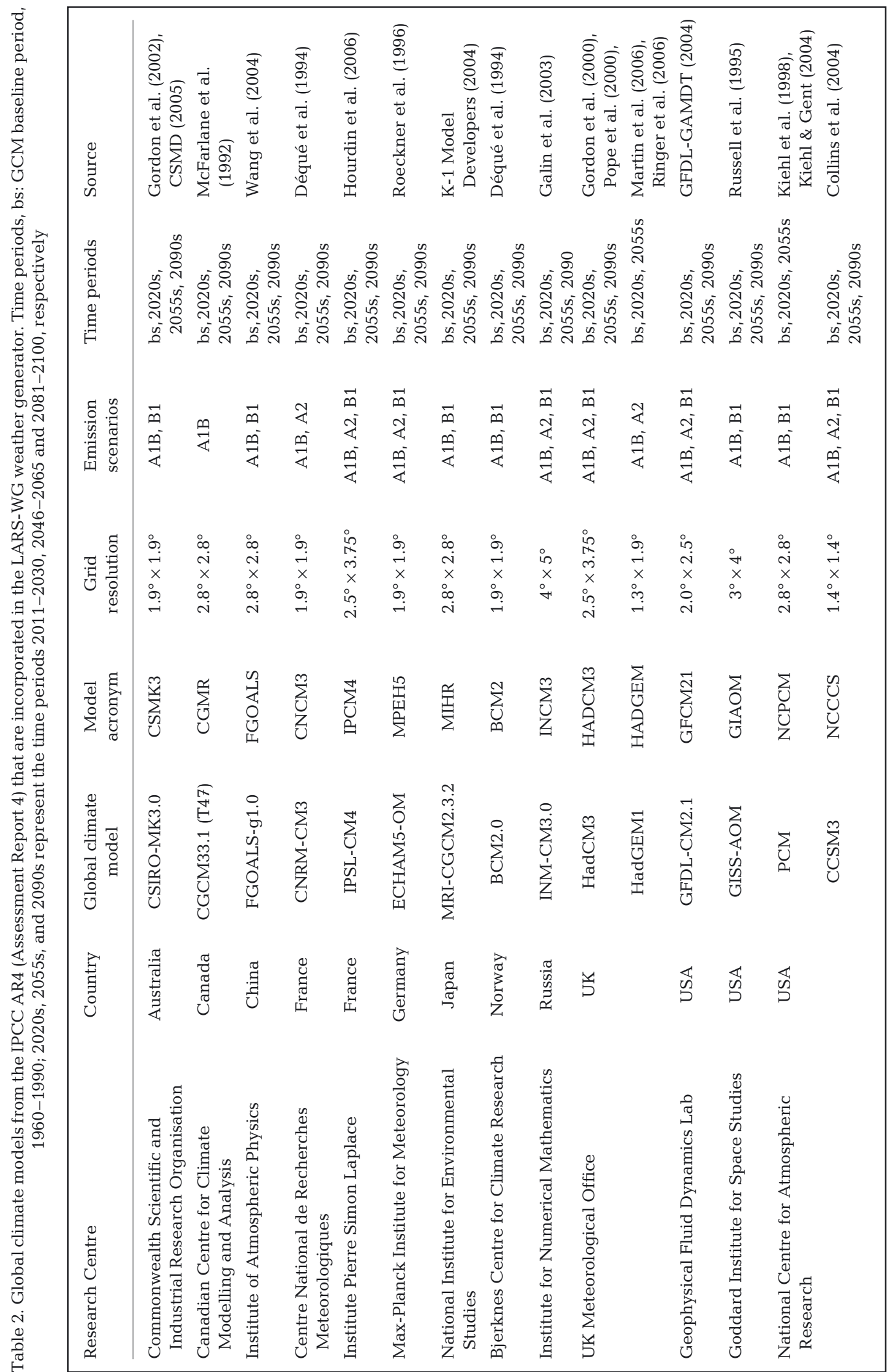


Table 3. $\mathrm{CO}_{2}$ concentrations (ppm) for selected climate scenarios specified in the Special Report on Emission Scenarios (SRES) (Nakicenovic \& Swart 2000). $\mathrm{CO}_{2}$ concentration for the baseline scenario is $334 \mathrm{ppm}$

\begin{tabular}{|c|c|c|c|c|}
\hline & Key assumptions & 2011-2030 & $2046-2065$ & $2081-2100$ \\
\hline B1 & $\begin{array}{l}\text { The sustainable world: rapid change in economic structures, 'dematerial } \\
\text { ization' including improved equity, and environmental concern. There is a } \\
\text { global concern regarding environmental and social sustainability and more } \\
\text { effort in introducing clean technologies. The global population reaches } \\
7 \text { billion by } 2100 .\end{array}$ & 410 & 492 & 538 \\
\hline B2 & $\begin{array}{l}\text { The world of technological inequalities: a heterogeneous society emphasising } \\
\text { local solutions to economic, social, and environmental sustainability rather } \\
\text { than global solutions. Human welfare, equality and environmental protection } \\
\text { all have high priority. }\end{array}$ & 406 & 486 & 581 \\
\hline A1B & $\begin{array}{l}\text { The rich world: characterised by very rapid economic growth }\left(3 \% \mathrm{yr}^{-1}\right) \text {, low } \\
\text { population growth }\left(0.27 \% \mathrm{yr}^{-1}\right) \text {, and rapid introduction of new and more } \\
\text { efficient technology. Globally, there is economic and cultural convergence } \\
\text { and capacity building, with a substantial reduction in regional differences in } \\
\text { per capita income. }\end{array}$ & 418 & 541 & 674 \\
\hline A2 & $\begin{array}{l}\text { The separated world: cultural identities are separating the different regions, } \\
\text { making the world more heterogeneous and international cooperation less likely. } \\
\text { Family values, local traditions, and high population growth }\left(0.83 \% \mathrm{yr}^{-1}\right) \text { are } \\
\text { emphasised. Less focus on economic growth }\left(1.65 \% \mathrm{yr}^{-1}\right) \text { and material wealth. }\end{array}$ & 414 & 545 & 754 \\
\hline
\end{tabular}

\section{CONCLUSIONS}

We have created a prototype dataset of local-scale daily climate scenarios, ELPIS, which currently consists of LARS-WG site parameters at $25 \mathrm{~km}$ grids across Europe for the period 1982-2008 and climate predictions from the multi-model ensemble of 15 GCMs used in the 2007 IPCC Assessment Report. Using the LARSWG weather generator, daily climate scenarios can be generated at any location in Europe for the future periods corresponding to 2020, 2055 and 2090 and several emission scenarios. The use of the AR4 multi-model ensemble allows the assessment, not only of the magnitude of the impact, but also of the uncertainty of impact predictions. ELPIS is designed for use in conjunction with process-based impact models, such as crop simulation models, which require local-scale daily weather as one of their inputs.

The performance of LARS-WG at nearly 12000 sites (grids) from the CGMS dataset has been assessed using statistical tests. The K-S nonparametric test was used to compare distributions of daily values for climatic variables, and the $t$-test was used to compare monthly mean values. Overall performance was good. For sites where the number of significant test results was larger than expected, more detailed inspection showed that the discrepancy between observed and simulated data is likely to have very little effect on the outcome of process-based impact models, such as crop simulation models.

We are planning to incorporate predictions from the multi-model ensemble of 14 regional models (RCM) from the EU-FW6 ENSEMBLES project. Model predictions were developed for Europe with the spatial resolution of $25 \mathrm{~km}$ (and/or $50 \mathrm{~km}$ ) and for the period 1951-2050 (or 1951-2100 for some RCMs). The daily outputs from the ENSEMBLES RCMs have recently been made available online at the project website (http://ensemblesrt3.dmi.dk). Regional climate models have shown a substantial improvement in modelling spatial weather patterns compared with global models due to much finer spatial resolution (Beniston et al. 2007, Salon et al. 2008). Incorporation of ENSEMBLES data will provide much better spatial resolution of predicted climatic changes for Europe and will allow incorporation of changes in climatic variability as well as changes in mean climate into local-scale climate scenarios.

Data series of the CGMS database have recently been revised. After regenerating the parameter set, it will be made available to the scientific community for impact assessment.

Acknowledgements. We thank S. Welham for her comments, and D. Fumagalli for setting the software system to generate parameters and data series at JRC. We also thank the Model and Data Group (M\&D) at the Max-Planck Institute for Meteorology, with funding from the Federal Ministry for Education and Research and the German Climate Computing Centre (DKRZ), for providing access to data and technical assistance. Rothamsted Research receives grant-aided support from the Biotechnology and Biological Sciences Research Council of the UK (BBSRC). P.S. was supported by a grant (BB/F021038/1) from BBSRC. Work at JRC was partially funded by the project AgroScenari, Italian Ministry of Agriculture, Forests, and Food Policies. 


\section{LITERATURE CITED}

Ångström A (1924) Solar and terrestrial radiation. Q J R Meteorol Soc 50:121-125

Bardossy A (1997) Downscaling from GCMs to local climate through stochastic linkages. J Environ Manage 49:7-17

Barrow EM, Semenov MA (1995) Climate change scenarios with high spatial and temporal resolution for agricultural applications. Forestry 68:349-360

Barrow E, Hulme M, Semenov MA (1996) Effect of using different methods in the construction of climate change scenarios: examples from Europe. Clim Res 7:195-211

Beniston M, Stephenson DB, Christensen OB, Ferro CAT and others (2007) Future extreme events in European climate: an exploration of regional climate model projections. Clim Change 81:71-95

Bregaglio S, Donatelli M, Confalonieri R, Acutis M, Orlandini $S$ (2010) An integrated evaluation of thirteen modelling solutions for the generation of hourly values of air relative humidity. Theor Appl Climatol (in press) doi:10.1007/ s00704-010-0274-y

Collins WD, Hack JJ, Boville BA, Rasch PJ and others (2004) Description of the NCAR Community Atmosphere Model (CAM3.0). Technical Note TN-464+STR, National Center for Atmospheric Research, Boulder, CO

Confalonieri R, Acutis M, Bellocchi G, Donatelli M (2009) Multi-metric evaluation of the models WARM, CropSyst, and WOFOST for rice. Ecol Modell 220:1395-1410

Confalonieri R, Bellocchi G, Tarantola S, Acutis M, Donatelli M, Genovese G (2010) Sensitivity analysis of the rice model WARM in Europe: exploring the effects of different locations, climates and methods of analysis on model sensitivity to crop parameters. Environ Model Softw 25: 479-488

CSMD (Climate System Modeling Division) (2005) CSMD, 2005: an introduction to the first general operational climate model at the National Climate Center. China Meteorological Administration

- Déqué M, Dreveton C, Braun A, Cariolle D (1994) The ARPEGE/IFS atmosphere model: a contribution to the French community climate modeling. Clim Dyn 10:249-266

Donatelli M, Bellocchi G, Carlini L (2006) Sharing knowledge via software components: models on reference evapotranspiration. Eur J Agron 24:186-192

> Donatelli M, Bellocchi G, Habyarimana E, Confalonieri R, Micale F (2009) An extensible model library for generating wind speed data. Comput Electron Agr 69:165-170

- Frei C, Schär C (1998) A precipitation climatology of the Alps from high-resolution rain-gauge observations. Int J Climatol 18:873-900

Galin VY, Volodin EM, Smyshliaev SP (2003) Atmospheric general circulation model of INM RAS with ozone dynamics. Russ Meteorol Hydrol 5:13-22

GFDL-GAMDT (Global Atmospheric Model Development Team) (2004) The new GFDL global atmosphere and land model AM2-LM2: evaluation with prescribed SST simulations. J Clim 17:4641-4673

Gordon C, Cooper C, Senior CA, Banks H and others (2000) The simulation of SST, sea ice extents and ocean heat transports in a version of the Hadley Centre coupled model without flux adjustments. Clim Dyn 16:147-168

Gordon HB, Rotstayn LD, McGregor JL, Dix MR and others (2002) The CSIRO Mk3 Climate System Model. CSIRO Atmospheric Research, Aspendale, Australia

Hargreaves GL, Hargreaves GH, Riley JP (1985) Irrigation water requirements for Senegal River Basin. J Irrig Drain E-ASCE 111:265-275
Haylock MR, Hofstra N, Tank A, Klok EJ, Jones PD, New M (2008) A European daily high-resolution gridded data set of surface temperature and precipitation for 1950-2006. J Geophys Res 113, D20119, doi:10.1029/2008JD010201

- Hourdin F, Musat I, Bony S, Braconnot P and others (2006) The LMDZ4 general circulation model: climate performance and sensitivity to parametrized physics with emphasis on tropical convection. Clim Dyn 27:787-813

K-1 Model Developers (2004) K-1 Coupled Model (MIROC) description. Center for Climate System Research, University of Tokyo, Japan

> Kiehl JT, Gent PR (2004) The Community Climate System Model, Version 2. J Clim 17:3666-3682

- Kiehl JT, Hack JJ, Bonan GB, Boville BA, Williamson DL, Rasch PJ (1998) The National Center for Atmospheric Research Community Climate Model: CCM3. J Clim 11: 1131-1149

Klok EJ, Tank A (2009) Updated and extended European dataset of daily climate observations. Int J Climatol 29: $1182-1191$

- Lawless C, Semenov MA (2005) Assessing lead-time for predicting wheat growth using a crop simulation model. Agric For Meteorol 135:302-313

Martin GM, Ringer MA, Pope VD, Jones A, Dearden C, Hinton TJ (2006) The physical properties of the atmosphere in the new Hadley Centre Global Environmental Model (HadGEM1). I. Model description and global climatology. J Clim 19:1274-1301

> McFarlane NA, Boer GJ, Blanchet JP, Lazare M (1992) The Canadian Climate Centre second-generation general circulation model and its equilibrium climate. J Clim 5:1013-1044

> Mearns LO, Bogardi I, Giorgi F, Matyasovskey I, Paleski M (1999) Comparison of climate change scenarios generated from regional climate model experiments and statistical downscaling. J Geophys Res 104:6603-6621

> Murphy J (1999) An evaluation of statistical and dynamical techniques for downscaling local climate. J Clim 12: $2256-2284$

Nakicenovic N, Swart R (eds) (2000) Emissions scenarios. 2000. Special report of the Intergovernmental Panel on Climate Change. Cambridge University Press, Cambridge

Pope VD, Gallani ML, Rowntree PR, Stratton RA (2000) The impact of new physical parametrizations in the Hadley Centre climate model: HadAM3. Clim Dyn 16:123-146

Prescott JA (1940) Evaporation from a water surface in relation to solar radiation. T Roy Soc South Aust 64:114-118

Press WH, Teukolsky SA, Vetterling WT, Flannery BP (2002) Numerical recipes in $\mathrm{C}++$. The art of scientific computing. William H. Press, Cambridge University Press, Cambridge

> Racsko P, Szeidl L, Semenov M (1991) A serial approach to local stochastic weather models. Ecol Modell 57:27-41

> Ringer MA, Martin GM, Greeves CZ, Hinton TJ and others (2006) The physical properties of the atmosphere in the new Hadley Centre Global Environmental Model (HadGEM1). II. Aspects of variability and regional climate. J Clim 19:1302-1326

> Rodriguez D, Van Oijen M, Schapendonk A (1999) LINGRACC: a sink-source model to simulate the impact of climate change and management on grassland productivity. New Phytol 144:359-368

Roeckner E, Arpe K, Bengtsson L, Christoph M and others (1996) The atmospheric general circulation model ECHAM4: model description and simulation of present-day climate. Max-Planck-Institut für Meteorologie, Hamburg

Russell GL, Miller JR, Rind D (1995) A coupled atmosphereocean model for transient climate change studies. Atmosocean 33:683-730 
Salon S, Cossarini G, Libralato S, Gao X, Solidoro S, Giorgi F (2008) Downscaling experiment for the Venice lagoon. I. Validation of the present-day precipitation climatology. Clim Res 38:31-41

Schapendonk A, Stol W, van Kraalingen DWG, Bouman BAM (1998) LINGRA, a sink/source model to simulate grassland productivity in Europe. Eur J Agron 9:87-100

Semenov MA (2007) Development of high-resolution UKCIP02based climate change scenarios in the UK. Agric For Meteorol 144:127-138

Semenov MA (2008a) Extreme impacts of climate change on wheat in England and Wales. Asp Appl Biol 88:37-38

Semenov MA (2008b) Simulation of extreme weather events by a stochastic weather generator. Clim Res 35:203-212

Semenov MA, Stratonovitch P (2010) The use of multi-model ensembles from global climate models for impact assessments of climate change. Clim Res 41:1-14

Semenov MA, Porter JR, Delecolle R (1993) Climatic change and the growth and development of wheat in the UK and France. Eur J Agron 2:293-304

Semenov MA, Wolf J, Evans LG, Eckersten H, Iglesias A (1996) Comparison of wheat simulation models under climate change. 2. Application of climate change scenarios. Clim Res 7:271-281

Semenov MA, Brooks RJ, Barrow EM, Richardson CW (1998) Comparison of the WGEN and LARS-WG stochastic weather generators in diverse climates. Amer Soc Agric Engineers (ASAE), St. Joseph, MI, p 8

Solomon S, Qin D, Manning M, Marquis M and others (eds) (2007) Climate change 2007: the physical science basis.

Submitted: November 16, 2009; Accepted: April 19, 2010
Contribution of Working Group I to the fourth assessment report of the Intergovermental Panel on Climate Change. Cambridge University Press, New York

> Supit I, Van Kappel RR (1998) A simple method to estimate global radiation. Sol Energy 63:147-160

van der Goot E (1997) Technical description of interpolation and processing of meteorological data in CGMS. EC Joint Research Centre, Ispra, Italy

van Diepen CA, Wolf J, van Keulen H, Rappoldt C (1989) WOFOST: a simulation model of crop production. Soil Use Manag 5:16-24

Wang B, Wan H, Ji Z, Zhang X, Yu R, Yu Y, Liu H (2004) Design of a new dynamical core for global atmospheric models based on some efficient numerical methods. Sci China Ser A 47:4-21

> Wilby RL, Wigley TML, Conway D, Jones PD, Hewiston BC, Main J, Wilks DS (1998) Statistical downscaling of general circulation model output: a comparison of methods. Water Resour Res 34:2995-3008

> Wilks DS (1992) Adapting stochastic weather generation algorithms for climate change studies. Clim Change 22: 67-84

Wilks DS, Wilby RL (1999) The weather generation game: a review of stochastic weather models. Prog Phys Geogr 23: 329-357

Willis JC, Bohan DA, Choi YH, Conrad KF, Semenov MA (2006) Use of an individual-based model to forecast the effect of climate change on the dynamics, abundance and geographical range of the pest slug Deroceras reticulatum in the UK. Glob Change Biol 12:1643-1657

Proofs received from author(s): May 26, 2010 